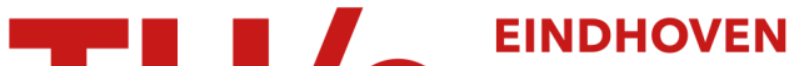 \\ UNIVERSITY OF \\ TECHNOLOGY
}

\section{Discrete part design by taking manufacturing restrictions into account}

Citation for published version (APA):

Delbressine, F. L. M., Hijink, J. A. W., \& van der Wolf, A. C. H. (1991). Discrete part design by taking manufacturing restrictions into account. CIRP Annals, 4O(1), 171-174.

Document status and date:

Published: 01/01/1991

\section{Document Version:}

Publisher's PDF, also known as Version of Record (includes final page, issue and volume numbers)

\section{Please check the document version of this publication:}

- A submitted manuscript is the version of the article upon submission and before peer-review. There can be important differences between the submitted version and the official published version of record. People interested in the research are advised to contact the author for the final version of the publication, or visit the $\mathrm{DOI}$ to the publisher's website.

- The final author version and the galley proof are versions of the publication after peer review.

- The final published version features the final layout of the paper including the volume, issue and page numbers.

Link to publication

\section{General rights}

Copyright and moral rights for the publications made accessible in the public portal are retained by the authors and/or other copyright owners and it is a condition of accessing publications that users recognise and abide by the legal requirements associated with these rights.

- Users may download and print one copy of any publication from the public portal for the purpose of private study or research.

- You may not further distribute the material or use it for any profit-making activity or commercial gain

- You may freely distribute the URL identifying the publication in the public portal.

If the publication is distributed under the terms of Article 25fa of the Dutch Copyright Act, indicated by the "Taverne" license above, please follow below link for the End User Agreement:

www.tue.nl/taverne

Take down policy

If you believe that this document breaches copyright please contact us at:

openaccess@tue.nl

providing details and we will investigate your claim. 


\title{
Discrete Part Design by Taking Manufacturing Restrictions into Account
}

\author{
F. L. M. Delbressine. J. A. W. Hijink - Submitted by A. C. H. van der Wolf (1) \\ Received on January 15, 1991
}

\begin{abstract}
A design methodology has been developed which takes mamufacturing restrictions into account in the design phase. This has been accomplished by defining manufacturable design transformations. This paper deals with manufacturable design transformations for a particular manuf acturing techinique i.o. milling operations. A typical example is shown to illustrate this approach.
\end{abstract}

Keywords: Design. CAD-CAM.

\section{Introduction}

The current market requires short production runs, a reduction in throughput time. and a greater prodict range. These requirenents inpose the need for a less time-consuming path from design to manufacture. for instance by integrating design and manufacturing.

\subsection{Design}

The aim of the design function is the translation of functional specifications into a prodhct that call perform the desired function(s). Within the context of this article, the design function consists of two phases: the conceptual phase and the geometrical phase. The concejtual phase deals with ideas about the product. The geometrical phase transforms the:se ideas into the design. Since the conceptual plase is an inventive process it cannot be readily formalized and therefore is left out within the present article. The primary purpose of design is the generation of an unambiguous, complete representation of the product. One that can be manufactured and accomplishes the desired functionality. The first requirement necessitates the enforcement of manufacturing restrictions in the geometrical design stage.

There are two ways of enforcing manufacturing restrictions:

- checking the completed design

- checking the initial state of the design and every design transformation which is being applied.

The first approach is, in our opinion, currently tow complicated to be performed automatically. The second approach is the one we will deal with. Essential in the chosen approach is the definition of design transformations that can be manufactured. These design transformations have been called Manufacturable Design Transformations. A particular kind of Manufacturable Design Transformations is the application of a Manufacturable Object, a design and manufacturing process plamning coun-terpart of a manufacturing transformation. A manufacturing transformation does consist out of the application of a combination of one or more tools, machines and setups in the manufacturing phase. A Manufacturable Object consists of two geometrical forms: an initial geometrical state and a final geometrical state together with a set of application rules. The application rules ensure that the Manufacturable Object can be applied. and thus the design can be manuf actured.
As counterpart of the limitation on the accuracy of the manufacturing process, the design operation "Implicit Location" is introduced. An Implicit Location specifies the location (position and orientation) of a solid object, or a Manufacturable Object. with constraints relative to another solid object.

In the design phase certain parameters must be available. For instance, the accuracy achievable with a Manufacturable Object. This may be accomplished by the incorporation of a model that knows' the accuracy of which the machine is capable to manufacture. Furthermore, the model 'knows' how to realize each Manufacturable Object according to its specification. The concept. which introduces the available machinery and equipment in the design phase, has been called the Manufacturing Machine Model. As has been explained before(1) the for the present purposes most suitable design representation is a combination of a Boundary Representation and a Constructive Solid Geometry representation. The first representation is a method for clescribing a physical solid object in terms of its topological boundary. The Constructive Solid Geometry representation is based on the fundamental concept that a solid object can be represented as a series of design transformations performed upon various simple solids. This is represented as a Constructive Solid Geonetry Tree of design transformations.

\subsection{Manufacturing Process Planning}

The Constructive Solid Geometry representation used specifies the initial state and the design transformations applied to obtain the final state of the design. The Constructive Solid Geometry Tree can thus be used as a guide for the generation of a manufacturing process plan i.e. it is a high level outline of the manufacturing process plan.

\section{The application context}

The concepts developed have been implemented in a sof tware package called Manufacturing Oriented Design. Essential iin this approach is the definition of what can be manufactured. For a single uanufacturing technology i.e. nilling, a few tool types and single piece or small batch manutacturing, what can be manufactured will be defined in such a way that they can be handled in the geometrical design phase. Milling has been chosen because it is a well formalized manufacturing technology. The tools chosen are ball-nosed mills, slot mills. face shell end mills. drills, and thread cutters. 


\section{Defining Manufacturable Design Transformations.}

As mentioned before a Manuf acturable Object consists of two geometrical forms: the initial geometrical state, the final geometrical state. together with a set of application rules. Which facts determine whether a Manuf acturable Object can be manuf actured?

- Firstly, the difference between the current intermediate geometrical state and the next intermediate geometrical state. thus the material that has to be removed. called a "delta volume" (Figure 1).

- Secondly. the application location of the Manuf acturable Object. and

- the desired tolerances.

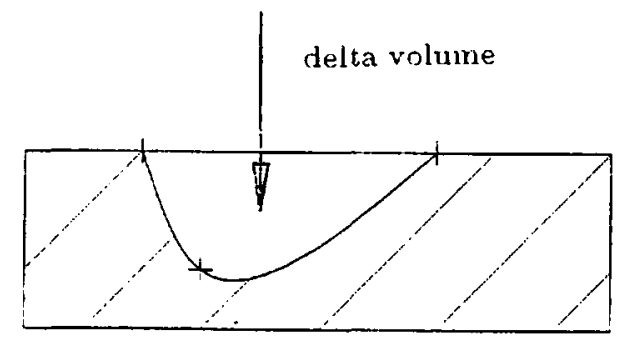

Figure 1. A delta volume.

\subsection{The "delta volume"}

The "delta volume" has to be generated by the necessary tool(s) and the movements of the tool(s) relative to the workpiece. The "delta volume" is generated in the design pluase by a boolean intersection of a "tools cutting parts volume" and the solid object. The solid object is the design equivalent of the workpiece to which the design transformation is being applied (Figure 2). The "tools cutting parts volume" is the design equivalent of a volume generated by the cutting parts of one or more tools.

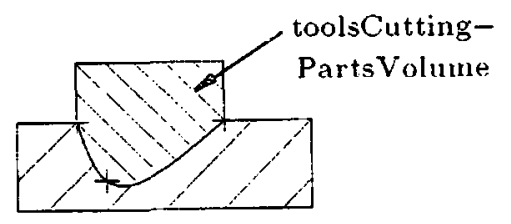

Figure 2. A tools cutting parts volume

In mathematical form:

$$
\begin{aligned}
& \text { toolsCuttingParts Volume }= \\
& F(\text { tools, tool movements) }
\end{aligned}
$$

$F$ is a function. The inverse transformation from "tools cutting parts volume" to tool(s) and tool movenents is a one-to-many mapping.

deltaVolume $=$

toolsCuttingParts Volume $\cap$ solidOb ject (2)

Again the operation $n$ is a function, which in this case returns the intersection of the "tools cutting parts volume" and the solid object. The inverse operation given a "delta volume" determine the "tools cutting parts volume", is a one-to-many mapping. This property for instance can be employed when an approach direction cannot be used, for instance due to obstacles. It also allows the use of different tools belonging to the same category.

To continue we need to define another volume: the "machine and tools volume". The "tools cutting parts volume" is created by the movements of the cutting parts of the tool(s) relative to the workpiece. The "machine and tools volume" is the volume occupied by the necessary movements of the tool(s) and the machine to genera te the "tools cutting parts volume".

The foregoing assumes that a "delta volume" is manufactured on a single inachine. The assumption is justified because a "delta volume" depending on more than one manufacturing machine can always be split into two or more "delta volumes" each of which depends on one machine.

Which criteria have to be attached to:

- the relations between the defined volumes and the solid object.

- the function $F$

in order to guarantee that a Manufacturable Object can be manuf actured?

The intersection of the solid object and the corresponding "tools cutting parts volume" has to be equal to the "delta volume" (Figure 3), else unintended material will be removed.

It is also necessary to check whether the "machine and tools" volune minus the "tools cutting parts volume" intersects with the next intermediate state. In that case a collision will occur while manufacturing the desired "delta volume".

When the "delta volume" conforms to special properties, an inverse transformation from "delta volume" to the selection of tool(s) and their movement will exist, making it possible to gencrate, given

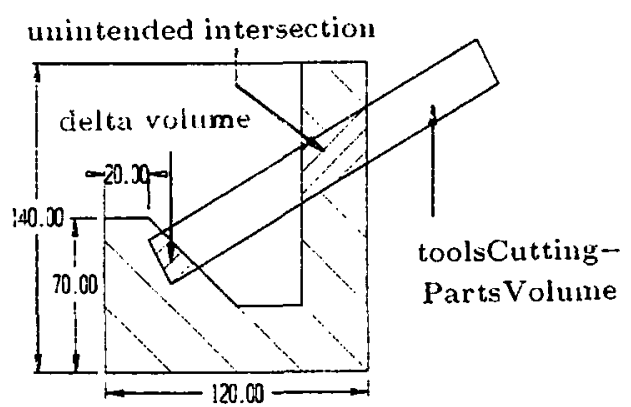

Figure 3. The intersection of the solid object and a "tools cutting parts volume"

a set of suitable tools, the toolpathes needed to manufacture the desired "delta volume". The main problem is the existence of a general inverse function F. Fundamental research is needed to determine which properties of the "delta volume" determine whether a manufacturable "tools cutting parts volume" can be found. In practice, therefore, "tools cutting parts volumes" are defined empirically, using experience of previously manufactured shapes. They are of ten called "manufacturing features". For the limited kind of tools specified, some general criteria for manufacturable "tools cutting parts volumes" can be given.

Another problem is that the "machine and tools volume" is depending on the chosen set-ups of the workpiece. Usually the set-up's are selected af ter the geometrical design has been completed due to minimization of the number of set-up's. Therefore, in practical applications. very of ten not the "machine and tools volume" is used for collision checking but a 
kind of "tools volume". The "tools volume" is the volume generated by the movements of the complete tool(s).

\subsection{The application location of a "delta volume"}

An important aspect of the application location of a "delta volume" is whether it can be approached and withdrawn from with the given machine and cool(s). An important criterium is: the "machine and tools volume": with the tool(s) in an approach/withdraw state. may not intersect with the solid object. A suitable method for finding collision-free pathes can be found in (2).

From the "delta volume" and its application location (Figure 7 ), approach and withdraw directions are inferrable (Figure 4).

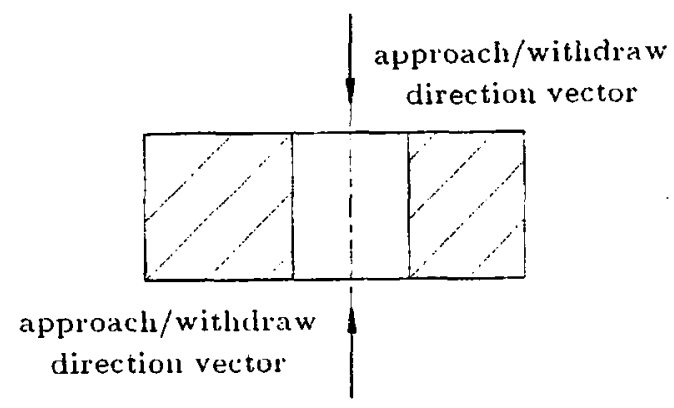

Figure 4. A through hole.

A necessary, but not sufficient criterium. for multiple approach and withdraw directions is that at least two pairs of faces. respectively of the solid object and the "delta volume", are coincident (Figure 5). From each pair one face has to belong to the solid object and the other to the "delta volune".

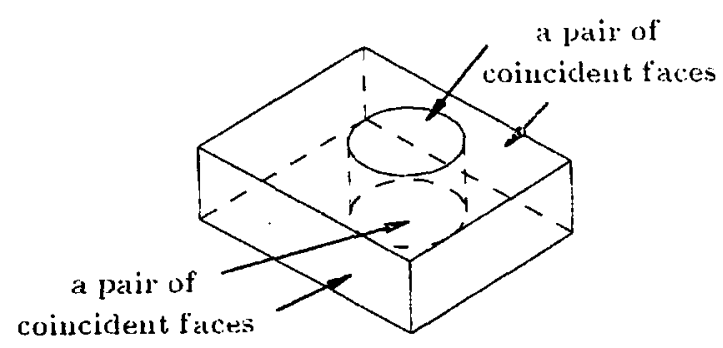

Figure 5. Coincident faces of the "delta volume" and the solicl object.

\subsection{The desired tolerances of "delta volumes"}

In the design phase the desired tolerance of a "delta volume" is compared with the set of suitable machine-tools. The abilities of a machine-tool determine whether it is suitable. Each machine-tool has a "Manufacturing Machine Model" which kuows which manufacturing techmology and what accuracy is reachable, given the type of Manufacturable Object and the material of the workpiece.

\section{Manufacturing Oriented Design.}

As mentioned before. it is not yet possible to specify the properties a "delta volume" has to fulfill to be manufacturable. Furthermore, the transformation from "delta volume" to "tools cutting parts volume" is a one-to-many mapping. Therefore, Manufacturable Objects have been defined, they are a kind of "tools cutting parts volumes". The user can apply the Manufacturable Objects to the solid object. The Manufacturable Object and the Manufacturing Machine Models together "know" how to manufacture the desired "delta volume". For our purpose we have identified some "Manufacturable Object" types (see Figure 6).

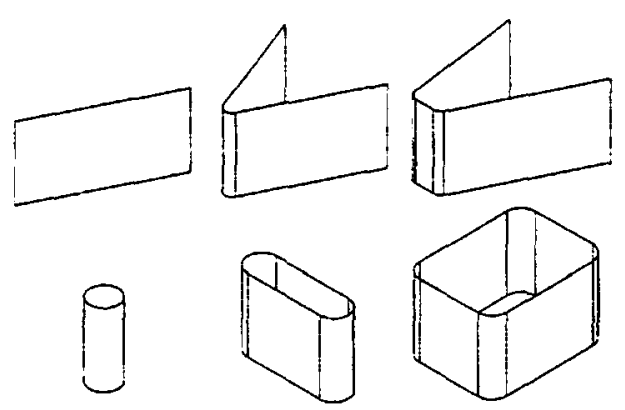

Figure 6. The set of available Manufacturable Objects.

These "Manufacturable Objects" have, if possible. multiple approach/withdraw direction vectors attached to them.

\section{A typical example.}

As an example of the approach taken a typical example has been designed and manufactured, see Figure 7.

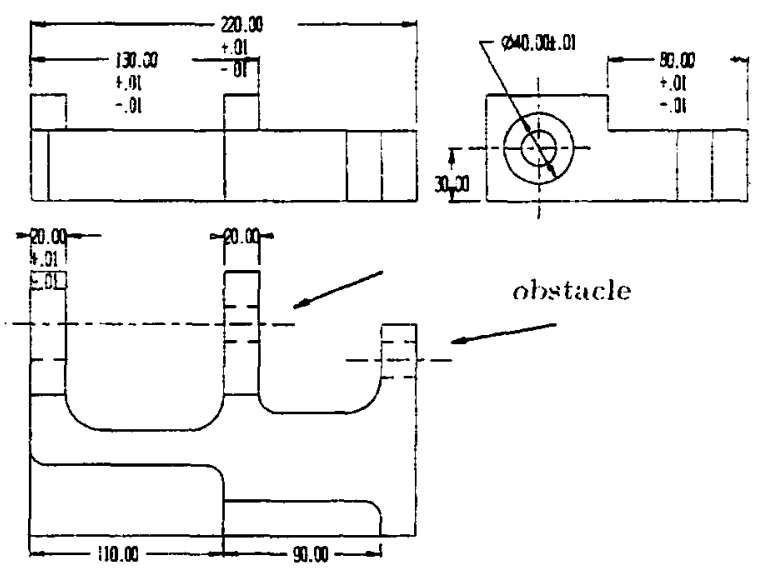

Figure 7. An example product.

The pointed to cylindrical hole has only one approach/withdraw vector attached to it: due to an obstacle.

\section{Conclusions and recommendations.}

Our approach assumes that the sequence, inherent in the Design Transformations Tree, will not be changed in the manufacturing process planning stage. The desired locational accuracy of a Manufacturable Object and the chosen set-up's sometines 
necessitate a change in this sequence. This is currently not allowed, for instance referential itens may not exist when they are needed (see figure 8).

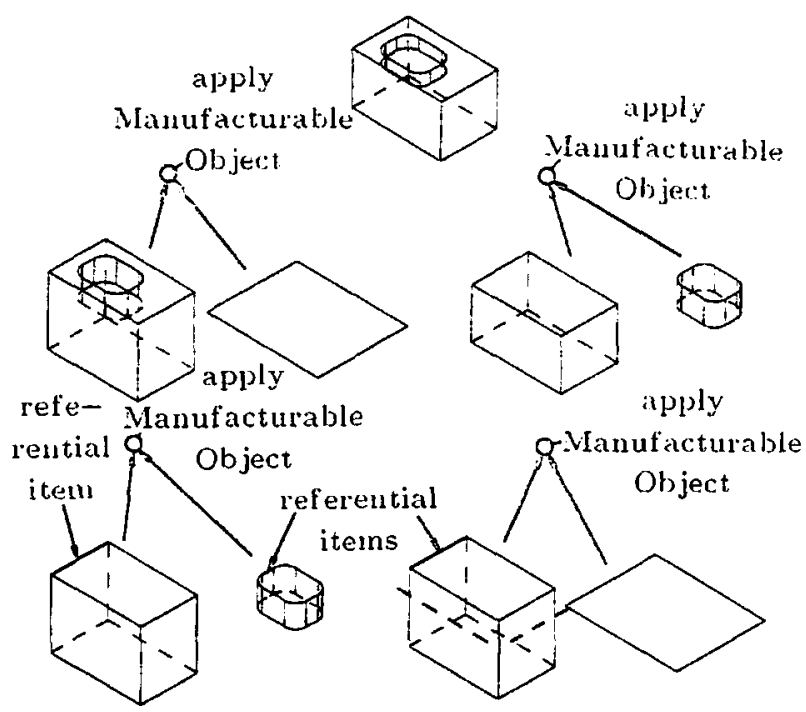

Figure 8. Two different Manufacturing Trees

Currently optimization in the tooling usage is not performed. It is desirable to perform roughing first. An optimization of tooling usage is needed in order to prevent unnecessary tool changes. Automatic generation of set-ups (3) and fixtures is possible because information is available on tolerances and reference items. It is not yet implemented in the system under discussion.

Currently not included in the developed system is a cost estimate of the designed product. We intend to incorporate a cost range estimate function which will be based on the set of available manufacturing machines.

Automatic measuring of products is possible, assuming that the referential items still exist when the sequence of the manufacturing process planning tree is not the same as the design sequence.

Very of ten a product is depending simultaneously on two or more manuf acturing techniques. For instance, a product manufactured by welding and milling. The design of the product has thus to comply with two interacting manuf acturing techniques.

Manufacturability is a quite difficult conception even for well formalized manufacturing techniques such as milling. For instance, which criteria have to be attached to the geometry of "delta volumes" to assure that a corresponding "tools cutting parts volume" can be found which can be mamufactured?

The approach chosen has one major problem, it assumes that the next intermediate state does not dictate the initial intermediate state. In certain cases. this is not true. For instance, see figure 9.

The next intermediate state in figure 9 is the bended strip, this state dictates the initial intermediate state for instance due to non-elastic material properties. The result is that the whole design tree which has lead to the initial intermediate state has to be revised. An automatic revision would necessitate
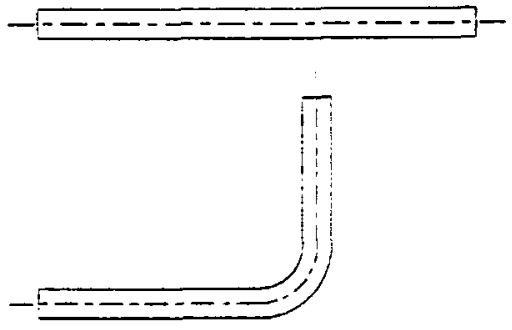

Figure 9. Bending a strip.

much knowledye about what can be manufactured. This is currently not available.

A possible extension of the developed approach might be the incorporation of models of functional components. whose geometry has been created automatically with the approach shown in this paper. The geometry and the manuf acturing technique(s) of the physical component can be made dependent on the functional requirements of the physical component (4).

(1) Delbressine F.L.M., van der Wolf A.C.H. 1990. Integrating Design and Manufacturing, CIRP Anuals 39/1. p 149-152.

(2) Lozano-Perez T.. Automatic Planning of Manipulator Transfer Movements, IEEE Vol SMIC-11, no 10, 1981.

(3) Kals H.J.J, Boerma J.R.. Fixture Design with Fixes: the Automatic Selection of Positioning. Clamping and Support Features for Prismatic Parts, Annals of the CIRP Vol. 38/1/1989.

(4) Schmekel H., Sohlenius G., Functional Models and Design Solutions. Annals of the CIRP Vol. $38 / 1 / 1989$.

(5) Woo T.C.. Turkovich von B.F.. Visibility Map and its Application to Nimerical Control, Annals of the CIFP Vol. 39/1/1990.

(6) Brooks R.A.. Solving the Find-path Problem by good Representation of Free Space, proceedings of the National Conference on Artificial Intelligence, 1982 